\title{
Diferentes métodos de controle de plantas indesejáveis em pastagem nativa $^{1}$
}

\author{
Luiz Giovani de Pellegrini ${ }^{2}$, Carlos Nabinger ${ }^{3}$, Paulo César de Faccio Carvalho ${ }^{3}$, Mikael \\ Neumann 4
}

\footnotetext{
${ }^{1}$ Parte da dissertação de Mestrado em Zootecnia do primeiro autor, UFRGS.

2 Doutorando da UFPR. Rua Benjamim Constant, n. 768, ap. 404, CEP: 97050-020, Santa Maria, RS

3 Curso de Agronomia da UFRGS.

${ }^{4}$ Curso de Medicina Veterinária da UNICENTRO.
}

RESUMO - O experimento foi desenvolvido em área de pastagem nativa representativa da transição entre a Serra do Sudeste e a Depressão Central do Rio Grande do Sul, onde as espécies indesejáveis foram representadas especialmente por carqueja (Baccharis trimera (Less.) DC.), caraguatá (Eryngium horridum (Spreng.) Less.) e alecrim (Vernonia nudiflora Less.) Foram avaliados os efeitos iniciais de dois métodos de controle de espécies indesejáveis (até 60 dias após aplicação) sobre a produção de forragem, a dinâmica da vegetação e a eficiência de controle: sem-controle; controle mecânico; e controle químico (herbicida comercial à base de Picloram $[64 \mathrm{~g} / \mathrm{L}]+2,4-\mathrm{D}[240 \mathrm{~g} / \mathrm{L}]$, na dosagem de $5 \mathrm{~L}$ do produto comercial/ha). Os tratamentos foram arranjados em um delineamento em blocos ao acaso, com quatro repetições. A massa gramíneas verdes secas e a massa total de MS não diferiram entre os métodos de controle. Foram obtidos valores de 587,9; 472,0 e $0 \mathrm{~kg}$ de MS com o controle mecânico, o controle químico e sem-controle, respectivamente, o que comprova influência do método de controle sobre a massa de forragem de leguminosas. A eficiência de controle das espécies indesejáveis, em comparação à ausência de controle, foi de $76,2 \%$ para o controle químico e $27,9 \%$ para o controle mecânico. A eficiência de controle de espécies, sob aspectos de freqüência dos componentes da pastagem, evidenciou que o controle mecânico não foi eficiente aos 60 dias após aplicação no controle de plantas de alecrim no segundo toque $(-27,7 \%)$ e plantas de caraguatá no primeiro toque $(-30,0 \%)$

Palavras-chave: campo nativo, controle de invasoras, eficiência de controle, roçada

\section{Different methods for controlling undesirable plants in native pasture}

\begin{abstract}
The study was conducted in a representative native pasture area in the transition between the Serra do Sudeste and Depressão Central of RS. The main undesirable species were represented by: carqueja (Baccharis trimera (Less.) DC.), caraguatá (Eryngium horridum (Spreng.) Less.) and alecrim (Vernonia nudiflora Less). It was evaluated the initial effect (until 60 days after application) of two methods of controlling undesirable plants on forage production, vegetation dynamics, and control efficiency: $\mathrm{T}_{1}$ - without control (control, SC), $\mathrm{T}_{2}$ - mechanical control (mechanic control, CM) and $\mathrm{T}_{3}$ - chemical control (commercial herbicide composed by Picloram $(64 \mathrm{~g} / \mathrm{L})+2.4-\mathrm{D}(240 \mathrm{~g} / \mathrm{L})$, in the dosage of $5 \mathrm{~L}$ commercial product/ha, CQ). The treatments were organized in a complete block design, with four replications. There were no differences among treatments for the green dry matter of grasses and total DM. The forage legume biomass differed among treatments, with values of $587.9,472.0$ and $0 \mathrm{~kg} / \mathrm{ha}$ of DM in the CM, CQ and SQ, respectively. The control efficiency of undesirable species in this study was $76.2 \%$ for CQ and $27.9 \%$ for CM when compared to SC. The species control efficiency, in terms of frequency of pasture components, showed that the $\mathrm{CM}$ treatment was not efficient at 60 days after treatment application in the control of Vernonia nudiflora (Alecrim) in the second touch $(-27.7 \%)$ and Eryngium horridum (Caraguatá) in the first touch $(-30.0 \%)$.
\end{abstract}

Key Words: control efficiency, mowing, native grassland, weed control

\section{Introdução}

As pastagens naturais são fundamentais no desenvolvimento da pecuária de corte no Rio Grande do Sul, em razão de sua grande diversidade de espécies forrageiras e da relativa estabilidade de produção.
Nos campos naturais do Rio Grande do Sul, já foram identificadas mais de 400 espécies de gramíneas e mais de 150 espécies de leguminosas (Boldrini, 1997). Essa riqueza florística, aliada às condições edafoclimáticas predominantes, traz um fato pouco comum no restante do Brasil: a associação de espécies de crescimento estival, em especial 
de rota metabólica $\mathrm{C}_{4}$, e espécies de crescimento hibernal $\mathrm{C}_{3}$ (Moraes et al., 1995). No entanto, essa biodiversidade também é constituída de espécies de outras famílias nãoforrageiras e/ou muitas vezes tóxicas aos animais e que, em determinadas situações, se tornam indesejáveis ao adequado manejo das pastagens naturais visando eficiente produção animal.

Considera-se planta indesejável aquela que não se integra de forma contínua à dieta do animal e que, por sua freqüência, traz prejuízos ao sistema de forrageamento, pela redução significativa da freqüência e produção de espécies forrageiras desejáveis, com conseqüente diminuição da capacidade de suporte da pastagem e do desempenho animal (Nabinger, 2002). No Sul do Brasil, as principais plantas indesejáveis são: carqueja (Baccharis trimera (Less.) DC.), caraguatá (Eryngium horridum (Spreng.) Less.), alecrim (Vernonia nudiflora Less.), mio-mio (Baccharis coridifolia DC.) e chirca (Eupatorium buniifolium Hook) (Gonzaga, 1999).

No momento em que a proporção de espécies indesejáveis se torna um obstáculo para a produção animal, alguma medida de controle deve ser aplicada para melhorar essa pastagem. Montefiore \& Vola (1990) verificaram que uma cobertura de caraguatá com 55\% de ocupação chega a reduzir $43 \%$ da produção total de forragem. Segundo Vitória Filho (1985), essas espécies ainda competem por nutrientes, água, luz e espaço com as espécies forrageiras desejáveis, reduzindo a superfície pastoril dos campos.

No processo de melhoramento de campos naturais, aspectos como presença e proporção de espécies indesejáveis devem ser considerados, sob o ponto de vista da tecnologia a ser aplicada e do custo representado por esta tecnologia (Nabinger, 1980). Nuñez \& Del Puerto (1988) citaram que características morfofisiológicas de espécies indesejáveis, como a época de florescimento, a capacidade de rebrote e o potencial de germinação das sementes, devem ser analisadas nas diferentes etapas fenológicas da planta para que a escolha do método de controle a ser utilizado seja adequada. Os métodos de controle de plantas indesejáveis mais utilizados são os mecânicos (roçadas), os químicos (herbicidas), os biológicos, os físicos (fogo) e os de planejamento (culturais).

Neste estudo, objetivou-se avaliar os efeitos de diferentes métodos de controle de plantas indesejáveis em pastagem natural sobre a produção de forragem, a dinâmica da vegetação e a eficiência de controle nos primeiros dois meses após aplicação.

\section{Material e Métodos}

O experimento foi realizado nas instalações da propriedade rural "Casuarinas" no período de 26/12/2002 a 26/02/2003 (60 dias), em área de pastagem natural considerada típica da região. A propriedade está situada na zona de transição entre a Depressão Central e a Serra do Sudeste do Rio Grande do Sul, localizada no município de Cachoeira do Sul, no km 292 da rodovia BR-290, a 30,20 latitude Sul, 53,08 de longitude Oeste, com altitude de $95 \mathrm{~m}$. O clima predominante da região é o Cfa (subtropical úmido), conforme a classificação de Köppen, com precipitação média anual de $1.400 \mathrm{~mm}$ e temperatura média anual de $20^{\circ} \mathrm{C}$ (Moreno, 1961).

O solo da área experimental, classificado como argissolo vermelho distrófico típico (EMBRAPA, 1999), foi amostrado em 20/12/2002 e apresentou as seguintes características químicas: pH água: 5,$1 ; \mathrm{P}: 2,9 \mathrm{mg} / \mathrm{L}$; MO: $2,8 \mathrm{~g} / \mathrm{kg}$; Al: 0,5 cmol/L; Ca: $2,1 \mathrm{cmol} / \mathrm{L} ; \mathrm{Mg}: 1,0 \mathrm{cmol} / \mathrm{L}$. CTC efetiva: $7,7 \mathrm{cmol} / \mathrm{L}$; e saturação por base: $43 \%$.

Foram testados os efeitos de dois métodos de controle de plantas indesejáveis sobre a produção de forragem e a dinâmica da vegetação: sem-controle; controle mecânico; e controle químico (herbicida comercial Tordon, à base de Picloram (64 g/L) +2,4-D (240 g/L), na dosagem de $5 \mathrm{~L} / \mathrm{ha})$. Os tratamentos foram arranjados em um delineamento em blocos ao acaso, com quatro repetições para cada tratamento, de modo que o bloqueamento foi definido de acordo com a declividade do terreno. A unidade experimental, com área total de 0,5 ha, foi composta por uma faixa de pastagem natural de $1.250 \mathrm{~m}^{2}$.

A aplicação dos métodos de controle ocorreu em 26/12/ 2002, dez dias após a exclusão da área ao pastejo. Para aplicação do controle mecânico, utilizou-se uma roçadeira hidráulica tratorizada, com regulagem de altura de corte entre 10 e $15 \mathrm{~cm}$ do solo. No controle químico, utilizou-se um pulverizador pressurizado tratorizado, regulado para aplicação de $270 \mathrm{~L} /$ ha da mistura água + herbicida comercial Tordon (Picloram + 2,4-D), na dosagem de $5 \mathrm{~L}$ de produto comercial por hectare.

Os efeitos dos métodos de controle foram avaliados por meio da produção da biomassa aérea total e da sua composição botânica, determinadas aos $20(15 / 1 / 2003)$ e 60 dias (24/2/2003) após aplicação dos métodos de controle, mediante corte (rente ao solo) da massa contida em quatro quadrados de $0,5 \times 0,5 \mathrm{~m}\left(0,25 \mathrm{~m}^{2}\right)$ locados aleatoriamente a cada ocasião, em cada unidade experimental. Recolheu-se todo o material presente na superficie (inclusive o mantilho) 
e, após pesagem da massa total fresca, resgatou-se uma subamostra representativa de $0,8 \mathrm{~kg}$ para separação manual das frações gramíneas, leguminosas, espécies indesejáveis vivas, espécies indesejáveis mortas e material senescente das demais espécies. As frações foram secas em estufa de ventilação forçada a $60^{\circ} \mathrm{C}$, por 72 horas, para estimativa do teor de MS de cada componente. Os resultados da massa total e de cada fração foram extrapolados para $\mathrm{kg}$ de MS por ha $(\mathrm{kg} / \mathrm{MS} / \mathrm{ha})$, enquanto a composição botânica foi calculada por meio da participação percentual de cada fração na MS total.

A taxa de acúmulo de biomassa aérea foi determinada pela diferença entre as massas de forragem determinadas aos 20 e aos 60 dias após aplicação dos métodos de controle (26/12/2002). A eficiência de controle foi estimada com base na composição botânica em cada método de controle, comparativamente ao percentual da massa de indesejáveis vivas existentes no sem-controle em cada data de amostragem. Essa variável também foi calculada, do mesmo modo, quanto à freqüência de participação ou ocorrência.

A freqüência de ocorrência das principais espécies indesejáveis e dos grupos de outras espécies foi medida aos 60 dias após aplicação do método de controle, pelo método do ponto modificado (Becker \& Crockett, 1973), utilizando-se de três transectas de $5 \mathrm{~m}$ cada, graduadas em pontos eqüidistantes de $10 \mathrm{~cm}$, locadas no sentido diagonal da parcela. Com auxílio de uma vareta em posição vertical no nível da vegetação, a cada $10 \mathrm{~cm}$ da transecta, identificaram-se os componentes gramíneas, leguminosas, carqueja, alecrim, caraguatá, outras espécies, sobretudo Senecio brasiliensis (Spreng.) Less., Sida rhombifolia L., cyperaceas, folhas largas, e material senescente, registrando-se a freqüência destas espécies no primeiro e segundo toque da vareta.

Os dados dos parâmetros relativos ao comportamento qualiquantitativo da pastagem e à eficiência de controle foram submetidos à análise de variância pelo programa estatístico SAS (1993). A comparação das médias foi realizada pelo teste Tukey a 5\% de significância, utilizando-se o modelo matemático: $\mathrm{Y}_{\mathrm{ijk}}=\mu+\mathrm{MC}_{\mathrm{i}}+\mathrm{B}_{\mathrm{j}}+(\mathrm{MC} * \mathrm{~B})_{\mathrm{ij}}+\mathrm{D}_{\mathrm{k}}$ $+(\mathrm{MC} * \mathrm{D})_{\mathrm{ik}}+\mathrm{E}_{\mathrm{ijkl}}$, em que: $\mathrm{Y}_{\mathrm{ijk}}=$ variável dependente; $\mu=$ média das observações; $\mathrm{MC}_{\mathrm{i}}=$ efeito dos métodos de controle de índice i, sendo 1 (sem-controle), 2 (mecânico: roçada), 3 (químico: herbicida); $\mathrm{B}_{\mathrm{j}}=$ efeito do bloco de índice $\mathrm{j} ;(\mathrm{MC} * \mathrm{~B})_{\mathrm{ij}}=$ efeito da interação método de controle de índice $\mathrm{i} \times$ bloco de índice $\mathrm{j}$ (Erro a); $\mathrm{D}_{\mathrm{k}}=$ efeito da data de controle de índice $\mathrm{k}$, em que $1=$ data 1 e $2=$ data 2 ; $(\mathrm{MC} * \mathrm{D})_{\mathrm{ij}}=$ efeito da interação método de controle de índice $\mathrm{i} \times$ data de controle de índice $\mathrm{k} ; \mathrm{E}_{\mathrm{ijkl}}=$ efeito do erro aleatório associado a cada observação (Erro b).
Os parâmetros relativos à freqüência de ocorrência dos componentes da pastagem foram analisados em um arranjo fatorial $3 \times 2$, composto de três métodos de controle de espécies indesejáveis e dois toques na vegetação. A comparação das médias foi realizada pelo teste Tukey para efeito principal ou pelo teste Pdiff em casos de interação método de controle $\times$ toque na vegetação, ambos a 5\% de significância (SAS, 1993), utilizando-se o modelo matemático: $\mathrm{Y}_{\mathrm{ijk}}=\mu+\mathrm{MC}_{\mathrm{i}}+\mathrm{B}_{\mathrm{j}}+(\mathrm{MC} * \mathrm{~B})_{\mathrm{ij}}+\mathrm{EV}_{\mathrm{k}}+(\mathrm{MC} * \mathrm{EV})_{\mathrm{ik}}+\mathrm{E}_{\mathrm{ijk}}$, em que: $\mathrm{Y}_{\mathrm{ijk}}=$ variável dependente; $\mu=$ média das observações; $\mathrm{MC}_{\mathrm{i}}=$ efeito dos métodos de controle de índice $\mathrm{i}$, em que 1 = sem-controle, 2 = mecânico (roçada) e 3 = químico (herbicida); $\mathrm{B}_{\mathrm{j}}=$ efeito do bloco de índice $\mathrm{j} ;(\mathrm{MC} * \mathrm{~B})_{\mathrm{ij}}=$ efeito da interação método de controle de índice $\mathrm{i} \times$ bloco de índice $\mathrm{j}$ (erro a); $\mathrm{EV}_{\mathrm{k}}=$ efeito do toque na vegetação de índice $\mathrm{k}$, em que 1 = primeiro toque e 2 = segundo toque; $(\mathrm{MC} * \mathrm{EV})_{\mathrm{ik}}=$ efeito da interação método de controle de índice $\mathrm{i} \times$ toque na vegetação de índice $\mathrm{k} ; \mathrm{E}_{\mathrm{ijk}}=$ efeito do erro aleatório associado a cada observação (erro b). A interação $(\mathrm{MC} * \mathrm{~B} * \mathrm{EV})_{\mathrm{ijk}}$ também foi inicialmente testada, no entanto, em razão da baixa magnitude, foi removida do modelo estatístico.

\section{Resultados e Discussão}

A participação percentual de gramíneas + leguminosas e de espécies indesejáveis na estrutura da pastagem e a eficiência de controle não foram influenciadas $(\mathrm{P}>0,05)$ pela interação método de controle $\times$ data de avaliação (Tabela 1).

Houve diferença significativa $(\mathrm{P}<0,05)$ entre os métodos de controle quanto à participação percentual dos componentes da pastagem e à eficiência de controle. Aos 20 dias após aplicação do método de controle, a porcentagem de participação de gramíneas + leguminosas passou a ser maior $(\mathrm{P}<0,05)$ nos controles químico $(100 \%)$ e mecânico $(77,5 \%)$ comparativamente à ausência de controle (49,9\%) . $\mathrm{Na}$ ausência de controle, a participação de gramíneas + leguminosas foi reduzida em decorrência da maior $(\mathrm{P}<0,05)$ participação de plantas indesejáveis (50,1\%), em comparação aos controles mecânico e químico $(22,5 \%$ e $0 \%$, respectivamente). A redução na participação de plantas indesejáveis na massa de forragem disponível ao pastejo evidencia principalmente a eficiência de controle dos métodos empregados, comprovando a viabilidade de utilização do controle químico sobre as espécies carqueja, alecrim e caraguatá.

A menor eficiência do controle mecânico $(55,1 \%)$ em comparação ao controle químico sobre as plantas indesejáveis não permite classificá-lo como inutilizável, uma vez que esse método possui menor custo de aplicação e favorece a composição florística da pastagem, uma vez que não 
eliminou a participação de espécies leguminosas nativas de alto valor nutritivo da estrutura física da pastagem.

Resultado semelhante, com roçadas, com 55\% de eficiência de controle foi encontrado por Girardi-deiro et al. (1999), no controle de alho macho (Sisyrinchium platense).

Na segunda data de avaliação (26/2/2003, aos 60 dias após a aplicação dos controles químico e mecânico), a porcentagem de participação de gramíneas + leguminosas não se alterou (Tabela 1) em relação à primeira avaliação (26/12/ 2002, aos 20 dias após a aplicação dos controles). A eficiência do controle mecânico reduziu significativamente da primeira $(55,1 \%)$ para a segunda data $(37,5 \%)$ de avaliação, como conseqüência da rebrota das plantas no período de 20 a 60 dias após a aplicação da roçada. Esse efeito negativo da rebrota das plantas indesejáveis pode ser minimizado na associação com outro método de controle seqüencial, como o biológico. A utilização do pastejo na área logo após a roçada poderia estar contribuindo para a diminuição ou até o desaparecimento das espécies indesejáveis na composição florística da pastagem.

O controle mecânico eliminou a porção da parte aérea das plantas indesejáveis, mas manteve parte das gemas axilares e todas as gemas basais, o que possibilita o rebrote, diferentemente do que se constatou no controle químico, o qual promoveu o desaparecimento das plantas indesejáveis por atuar sistemicamente sobre a planta, atingindo todas as regiões meristemáticas e axiais.
Houve diferença estatística significativa $(\mathrm{P}<0,05)$ entre os métodos de controle quanto à produção de massa de forragem de leguminosas, à participação percentual de leguminosas, de material senescente e de espécies indesejáveis vivas na composição da pastagem e à eficiência de controle. Os métodos de controle, no entanto, não diferiram $(\mathrm{P}>0,05)$ quando avaliadas a taxa de acúmulo médio diário, a produção de massa de forragem total de gramíneas e a participação percentual de gramíneas e espécies indesejáveis mortas na composição botânica (Tabela 2).

A taxa de acúmulo médio diário apresentou valores superiores aos encontrados por outros autores sob as mesmas condições deste experimento. Moojen (1991) determinou taxas de acúmulo de 11,4 e 13,6 kg/ha/dia para os meses de janeiro e fevereiro, respectivamente. Escosteguy (1990), por sua vez, determinou taxa de acúmulo de $24,4 \mathrm{~kg}$ de $\mathrm{MS} / \mathrm{ha} /$ dia para mesma época, em mesma área de trabalho. A alta variação entre os valores da taxa de acúmulo médio diário justificou-se pela alta variabilidade florística nas pastagens nativas, com valores médios de 28,8; 17,3 e $16,8 \mathrm{~kg}$ de $\mathrm{MS} / \mathrm{ha} /$ dia para o controle químico, sem-controle e controle mecânico, respectivamente. A alta variabilidade é uma constante em áreas de campo nativo e pode ser explicada pela grande variação na composição botânica e nas condições do solo (umidade, fertilidade e micro-relevo). Souza (1985) explica que as variações nos dados de produção decorrem, em parte, da variação sazonal dos fatores

Tabela 1 - Participação percentual dos componentes gramíneas + leguminosas e eficiência de controle de plantas indesejáveis na massa de forragem disponível de uma pastagem nativa aos 20 e 60 dias após aplicação dos controles mecânico e químico

Table 1 - Percentage of the components grasses + legumes in the available forage mass of a native grassland and control efficiency of undesirable plants, observed 20 and 60 days post-application of the mechanical and chemical methods

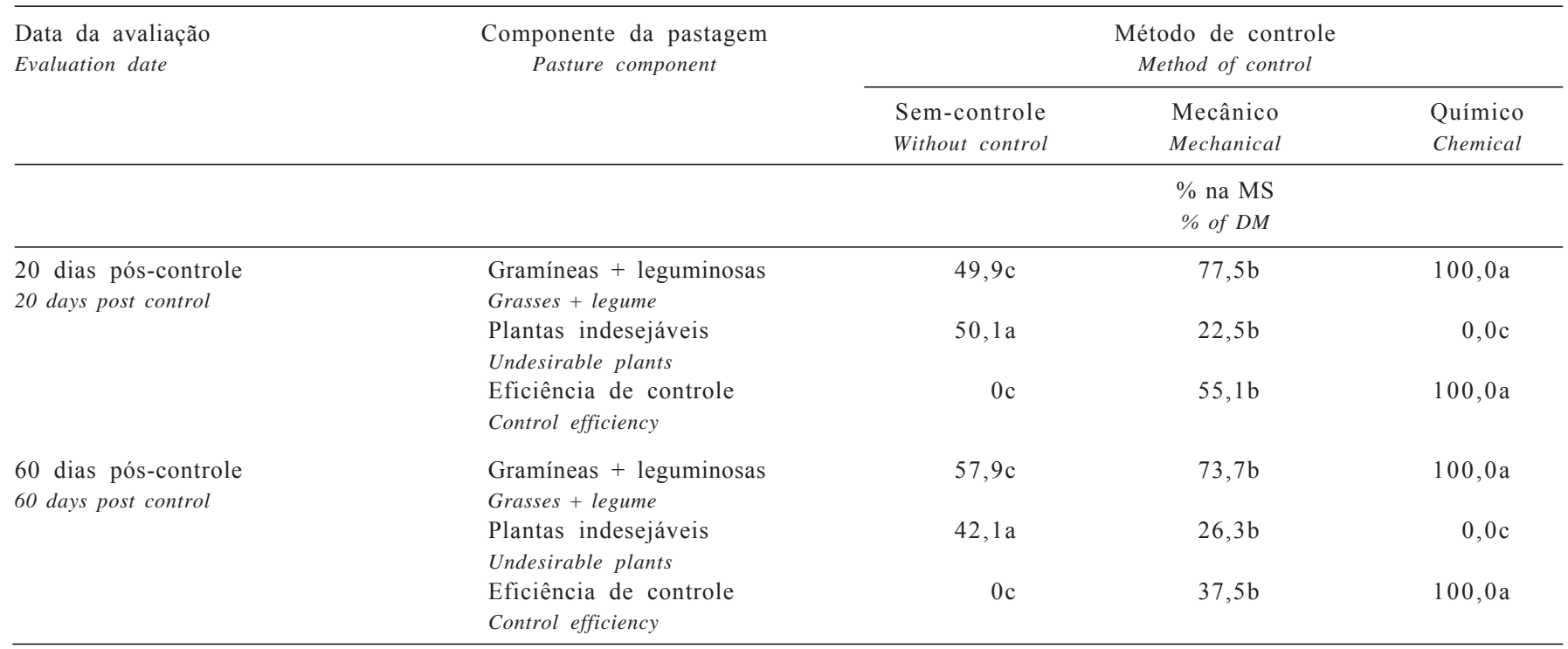


Tabela 2 - Comportamento agronômico qualiquantitativo da pastagem nativa após 60 dias do uso dos métodos de controle de plantas indesejáveis

Table 2 - Quantitative-qualitative agronomic behavior of the native grassland 60 days after the use of methods for controlling undesirable plants

\begin{tabular}{|c|c|c|c|}
\hline \multirow[t]{2}{*}{ Item } & \multicolumn{3}{|c|}{$\begin{array}{c}\text { Método de controle } \\
\text { Method of control }\end{array}$} \\
\hline & $\begin{array}{l}\text { Sem-controle } \\
\text { Without control }\end{array}$ & $\begin{array}{l}\text { Mecânico } \\
\text { Mechanical }\end{array}$ & $\begin{array}{l}\text { Químico } \\
\text { Chemical }\end{array}$ \\
\hline & \multicolumn{3}{|c|}{$\%$ na MS (\% of $D M)$} \\
\hline Taxa de acúmulo médio diário ${ }^{1}$ (Daily mean accumulation rate) & $17,3 \mathrm{a}$ & $16,8 \mathrm{a}$ & $28,8 \mathrm{a}$ \\
\hline Massa total de MS (Total mass of DM) & $5075,2 \mathrm{a}$ & $4841,5 \mathrm{a}$ & $4331,7 \mathrm{a}$ \\
\hline Massa de forragem de gramíneas (Grass forage mass) & $1553,9 \mathrm{a}$ & $1670,3 \mathrm{a}$ & $1835,6 \mathrm{a}$ \\
\hline Massa de forragem de leguminosas (Legume forage mass) & $472,0 \mathrm{a}$ & $587,9 \mathrm{a}$ & $0,0 \mathrm{~b}$ \\
\hline Composição botânica (Botanical composition) & \multicolumn{3}{|c|}{$\%$ na MS total (\% in DM total) } \\
\hline Gramíneas (Grasses) & $30,4 \mathrm{a}$ & $35,5 \mathrm{a}$ & $44,7 \mathrm{a}$ \\
\hline Leguminosas (Legume) & $8,8 \mathrm{a}$ & $11,9 \mathrm{a}$ & $0,0 \mathrm{~b}$ \\
\hline Material senescente (Senescent material) & $23,5 \mathrm{ab}$ & $19,9 \mathrm{~b}$ & $33,6 \mathrm{a}$ \\
\hline Indesejáveis vivas (Undesirable alive) & $28,5 \mathrm{a}$ & $15,8 \mathrm{a}$ & $0,0 \mathrm{~b}$ \\
\hline Indesejáveis mortas (Undesirable deceased) & $8,9 \mathrm{a}$ & $16,9 \mathrm{a}$ & $21,7 \mathrm{a}$ \\
\hline Eficiência de controle de plantas indesejáveis (Control efficiency of undesirable plants) & $0 \mathrm{c}$ & $27,9 \mathrm{~b}$ & $76,2 \mathrm{a}$ \\
\hline
\end{tabular}

1 Valores obtidos entre 20 e 60 dias, perfazendo um total de 40 dias de intervalo de crescimento.

Médias seguidas de letras diferentes na linha diferem $(P<0,05)$ pelo teste Tukey.

${ }^{1}$ Values obtained between 20 and 60 days, in a total of 40 days of growth interval.

Means followed by different letter in the same row are different $(P<0.05)$ by Tukey test.

climáticos, como precipitação, radiação solar, temperatura e, ainda, variações dentro das próprias estações do ano.

A taxa de crescimento da pastagem aumenta com a elevação da biomassa, em virtude do aumento da área foliar e da interceptação da radiação incidente (Harris, 1978). Esse fato justifica os valores elevados encontrados para a taxa de acúmulo encontrada neste trabalho. A eliminação ou diminuição das plantas competidoras (indesejáveis) promoveu o aumento da interceptação da radiação solar por espécies forrageiras dos estratos inferiores, que antes não recebiam radiação com mesma intensidade, justamente em virtude das características estruturais das plantas indesejáveis que ocupavam o estrato superior da pastagem. Além disso, outros aspectos relativos à competição por água e nutrientes também podem ter tido papel importante, embora de menor intensidade no curto prazo.

A massa total de forragem no sem-controle foi de $5.075,2 \mathrm{~kg}$ de MS/ha, com participação de $28,5 \%$ de indesejáveis vivas, o que pode justificar o maior valor de massa, uma vez que, para os controles mecânico e químico, à medida que diminuiu a participação de indesejáveis vivas, diminuiu também a massa total de forragem $15,8 \%$ e $4.841,5 \mathrm{~kg}$ de $\mathrm{MS} / \mathrm{ha}$ e $0,0 \%$ e $4.331,7 \mathrm{~kg}$ de $\mathrm{MS} / \mathrm{ha}$, respectivamente.

A massa de forragem de gramíneas não diferiu entre os métodos de controle e apresentou valores de 1.835,6; 1.670,3 e $1.553,9 \mathrm{~kg}$ de $\mathrm{MS} / \mathrm{ha}$ para o controle químico, o controle mecânico e sem-controle, respectivamente. Damé (1999) encontrou valores de massa de forragem de gramíneas próximos aos deste trabalho, com média de $1.429,5 \mathrm{~kg}$ de MS/ha. Na composição botânica da pastagem, o componente gramíneas foi o de maior participação. Os valores foram de 44,7; 35,5 e 30,4\% para controle químico, controle mecânico e sem-controle, respectivamente. Pacheco et al. (1987) demonstraram haver predominância de gramíneas em áreas de campo nativo. Santos (1998) e Damé (1999) também confirmaram esta afirmação e registraram 63,6 e $57 \%$, respectivamente, de participação de gramíneas nestas pastagens.

O componente plantas indesejáveis mortas e indesejáveis vivas teve maior e menor participação $(\mathrm{P}<0,05)$, respectivamente, no controle químico, o que promoveu menor competição entre as espécies indesejáveis e as espécies forrageiras desejáveis, ocasionando maior participação do componente gramíneas neste tratamento (44,7\%). À medida que aumentou a participação de plantas indesejáveis vivas e diminuiu a participação de indesejáveis mortas, houve redução da participação do componente gramíneas na composição botânica da pastagem.

Verificou-se ausência total de massa de forragem de leguminosas no controle químico, enquanto, no controle mecânico e no sem-controle, a massa de forragem de leguminosas foi de 587,9 e 472,0 kg de MS/ha, respectivamente. A ausência de leguminosas no controle químico também foi observada na composição botânica da pastagem, apesar da inexpressiva participação deste componente no controle mecânico $(11,9 \%)$ e no sem-controle $(8,8 \%)$. 
Santos (1998) explica que a baixa participação de leguminosas na massa de forragem se deve à competitividade por nutrientes com as gramíneas existentes na área e aos baixos níveis de fósforo em áreas de campo nativo. No entanto, segundo Damé (1999), com manejo e melhorias na fertilidade do solo, é possível elevar a participação deste componente nestes ecossistemas.

No controle químico, com a aplicação do herbicida $(2,4 \mathrm{D}+$ picloram $)$ não seletivo às leguminosas, houve morte das plantas e, conseqüentemente, o desaparecimento, uma vez que o herbicida atua sistemicamente sobre as plantas. Este fato proporcionou redução na qualidade da dieta ingerida pelos animais, pois, segundo Gomes (1984), a produção animal está diretamente relacionada à composição botânica da pastagem, em particular à proporção de leguminosas. Segundo Boldrini (1997), a qualidade de uma pastagem está intimamente relacionada à porcentagem de invasoras, gramíneas e leguminosas, visto que as leguminosas, em geral, possuem maior valor nutritivo em comparação às gramíneas.

De acordo com Rocha (1991), a característica mais marcante na presença da leguminosa na pastagem é o abastecimento contínuo de $\mathrm{N}$ via síntese biológica, que confere economicidade ao sistema produtivo com a incorporação deste nutriente, pois, na transformação da proteína da pastagem em carne, lã, peles ou leite, o N via fertilizante é o insumo mais oneroso.

No cálculo da eficiência de controle das espécies indesejáveis aos 60 dias após aplicação dos controles (Tabela 2), verificou-se que, no tratamento sem-controle, a participação total de espécies indesejáveis vivas e mortas foi de $37,4 \%$, porém, $8,9 \%$ de plantas indesejáveis caracterizaram-se mortas por efeitos relacionados ao clima e ao ciclo da planta. No controle mecânico, o total de indesejáveis vivas e mortas foi de $32,7 \%$ (16,9\% de plantas mortas), com taxa de desaparecimento em torno de $51,7 \%$ das plantas indesejáveis.

A eficiência de controle das espécies indesejáveis foi maior $(\mathrm{P}<0,05)$ no controle químico em relação ao controle mecânico. Em análise geral, a eficiência do controle químico apresentou grande desvantagem em virtude da eficiência no controle das leguminosas nativas. No controle mecânico, a eficiência foi menor, porém, com vantagem na manutenção das leguminosas na massa de forragem disponível (Tabela 2).

$\mathrm{Na}$ avaliação da freqüência das espécies carqueja e caraguatá, assim como na avaliação da eficiência de controle de alecrim e de caraguatá, não houve interação significativa $(\mathrm{P}>0,05)$ método de controle $\times$ toque na pastagem (Tabela 3), enquanto, na avaliação da freqüência das espécies gramíneas, leguminosas, alecrim e material senescente e na avaliação da eficiência de controle das leguminosas, houve

Tabela 3 - Freqüência dos componentes no primeiro e no segundo toque e eficiência de controle de espécies sobre a freqüência dos componentes da pastagem nativa após 60 dias da aplicação dos tratamentos

Table 3 - Frequency of the components of the native grassland in the first and second touch, and efficiency of control of undesirable species on the frequency of the components of the native grassland, 60 days after the application of the treatments

\begin{tabular}{|c|c|c|c|c|c|c|c|c|}
\hline \multirow{2}{*}{$\begin{array}{l}\text { Toque na } \\
\text { pastagem } \\
\text { Touch in pasture }\end{array}$} & \multirow[t]{2}{*}{$\begin{array}{l}\text { Método decontrole } \\
\text { Method of control }\end{array}$} & \multicolumn{7}{|c|}{$\begin{array}{c}\text { Componente da pastagem, } \% \\
\text { Component of the pasture, } \%\end{array}$} \\
\hline & & $\begin{array}{l}\text { Gramíneas } \\
\text { Grass }\end{array}$ & $\begin{array}{l}\text { Leguminosa } \\
\text { Legume }\end{array}$ & $\begin{array}{r}\text { Carqueja } \\
\text { Carqueja }\end{array}$ & $\begin{array}{l}\text { Alecrim } \\
\text { Alecrim }\end{array}$ & $\begin{array}{l}\text { Caraguatá } \\
\text { Caraguata }\end{array}$ & $\begin{array}{c}\text { Outras } \\
\text { Other }\end{array}$ & $\begin{array}{c}\mathrm{MS}^{2} \\
M S\end{array}$ \\
\hline Primeiro & Sem controle (Without control) & $62,2 b$ & $9,3 \mathrm{a}$ & $10,5 \mathrm{a}$ & $6,5 b$ & $3,8 \mathrm{~A}$ & $4,0 \mathrm{~A}$ & $3,7 \mathrm{c}$ \\
\hline \multirow[t]{2}{*}{ First } & Mecânico (Mechanical) & $60,8 \mathrm{~b}$ & $18,5 \mathrm{a}$ & $0,5 \mathrm{~b}$ & $8,3 \mathrm{~b}$ & $3,5 \mathrm{~A}$ & $2,7 \mathrm{~A}$ & $5,7 \mathrm{c}$ \\
\hline & Químico (Chemical) & $70,2 \mathrm{a}$ & $0,0 \mathrm{~d}$ & $0,0 \mathrm{~b}$ & $0,0 \mathrm{c}$ & $0,0 \mathrm{~B}$ & $3,5 \mathrm{~A}$ & $26,3 b$ \\
\hline Segundo & Sem controle (Without control) & $51,3 \mathrm{c}$ & $4,8 \mathrm{c}$ & $13,0 \mathrm{a}$ & $22,5 \mathrm{a}$ & $4,0 \mathrm{~A}$ & $2,8 \mathrm{~A}$ & $1,5 \mathrm{~d}$ \\
\hline \multirow[t]{4}{*}{ Second } & Mecânico (Mechanical) & $64,3 \mathrm{ab}$ & $6,8 \mathrm{bc}$ & $0,2 b$ & $19,3 \mathrm{a}$ & $5,2 \mathrm{~A}$ & $3,2 \mathrm{~A}$ & $1,0 \mathrm{~d}$ \\
\hline & Químico (Chemical) & $60,0 \mathrm{~b}$ & $0,2 \mathrm{~d}$ & $0,0 \mathrm{~b}$ & $0,0 \mathrm{c}$ & $0,0 \mathrm{~B}$ & $0,3 \mathrm{~A}$ & $39,5 \mathrm{a}$ \\
\hline & & \multicolumn{7}{|c|}{ Eficiência de controle, \% (Control efficiency, \%) } \\
\hline & & \multicolumn{2}{|c|}{$\begin{array}{l}\text { Leguminosa } \\
\text { Legume }\end{array}$} & $\begin{array}{l}\text { Carqueja } \\
\text { Carqueja }\end{array}$ & \multicolumn{2}{|r|}{$\begin{array}{l}\text { Alecrim } \\
\text { Alecrim }\end{array}$} & \multicolumn{2}{|c|}{$\begin{array}{l}\text { Caraguatá } \\
\text { Caraguata }\end{array}$} \\
\hline Primeiro & Químico (Chemical) & \multicolumn{2}{|c|}{$-98,9 d$} & $95,2 \mathrm{~A}$ & \multicolumn{2}{|r|}{$-27,7 \mathrm{~B}$} & \multicolumn{2}{|c|}{$7,9 \mathrm{~B}$} \\
\hline First & Químico (Chemical) & \multicolumn{2}{|c|}{$100,0 \mathrm{a}$} & $100,0 \mathrm{~A}$ & \multicolumn{2}{|r|}{$100,0 \mathrm{~A}$} & \multicolumn{2}{|c|}{$100,0 \mathrm{~A}$} \\
\hline Segundo & Mecânico (Mechanical) & \multicolumn{2}{|c|}{$-41,6 \mathrm{c}$} & $98,5 \mathrm{~A}$ & \multicolumn{2}{|r|}{$14,2 \mathrm{~B}$} & \multicolumn{2}{|c|}{$-30,0 \mathrm{~B}$} \\
\hline Second & Químico (Chemical) & \multicolumn{2}{|c|}{$95,8 \mathrm{~b}$} & $100,0 \mathrm{~A}$ & \multicolumn{2}{|r|}{$100,0 \mathrm{~A}$} & \multicolumn{2}{|c|}{$100,0 \mathrm{~A}$} \\
\hline
\end{tabular}

Médias seguidas de letras minúsculas diferentes na coluna diferem $(P<0,05)$ pelo teste $P$ diff.

Médias seguidas de letras maiúsculas diferentes na coluna diferem $(P<0,05)$ pelo teste Tukey.

2 Outras = especialmente Senecio brasiliensis (Spreng.) Less., Sida rhombifolia L., cyperaceas, folha larga; MS = material senescente

Means followed by different small letter in the same column, are different $(P<0.05)$ by Pdiff test.

Means followed by different capital letter in the same column are different $(P<0.05)$ by Tukey test.

${ }^{2}$ Other = Senecio brasiliensis (Spreng.) Less., Sida rhombifolia L., cyperaceas, large leaf; MS = senescent material. 
interação significativa $(\mathrm{P}<0,05)$ método de controle $\times$ toque na pastagem.

A freqüência de gramíneas (Tabela 3) no primeiro toque no controle mecânico aumentou em comparação ao sem controle, em virtude do efeito mecânico (roçada), pois, à medida que a parte aérea das plantas indesejáveis foi eliminada, abriu-se espaço para a exposição das gramíneas, fato confirmado pela eficiência de controle calculada sobre a freqüência dos componentes da pastagem, de modo que $98,5 \%$ das plantas de carqueja foram eliminadas no primeiro toque, assim como $14,2 \%$ das plantas de alecrim.

A eficiência do controle mecânico das plantas de alecrim no segundo toque, assim como a eficiência de controle do caraguatá no primeiro toque, não foi efetiva aos 60 dias após aplicação. Esses fatos podem ser justificados pelo comportamento dessas plantas à roçada. No momento em que sofreram o corte no controle mecânico, as plantas de alecrim emitiram brotações da base da planta original e, conseqüentemente, ocorreram estímulos para que de uma haste surgissem várias outras hastes filhas, ocasionando aumento da freqüência no segundo toque.

Situação inversa foi observada nas plantas de caraguatá, nas quais o corte da parte aérea da planta estimulou a brotação no centro da planta, que emitiu novas folhas, que cresceram no sentido vertical da pastagem, atingindo novamente o primeiro toque para, posteriormente, ocuparem espaço no sentido horizontal à medida que avançaram em maturidade (Tabela 3 ). O comportamento de rebrote das plantas pós-roçada explica a não-eficiência do controle mecânico após aos 60 dias de sua aplicação.

A ocorrência de carqueja foi afetada pelos controles mecânico e químico, tanto no primeiro como no segundo toque na pastagem. No controle químico, a freqüência do componente foi nula nos dois toques e proporcionou eficiência de controle de $100 \%$. O controle mecânico também apresentou mínima participação nos dois toques $(0,5 \%$ no primeiro e $0,2 \%$ no segundo toque), com eficiência de controle de $98,5 \%$ no segundo toque e de $95,2 \%$ no primeiro toque. Qualquer um dos métodos empregados foi eficiente no controle deste componente, o que permite optar pelo que ocasione menores prejuízos à estrutura da pastagem, visto que o controle químico apresenta grande efeito negativo na freqüência de leguminosas.

O controle químico foi eficiente no controle de espécies indesejáveis, embora tenha eliminado as leguminosas. A freqüência com que as leguminosas apareceram no controle mecânico (18,5\% no primeiro e $6,8 \%$ no segundo toque) indicam que sua participação é significante por alterar a qualidade da pastagem.

Resultados diferentes foram encontrados por Allegri (1978), que utilizou herbicida à base Picloram + 2,4 D e não observou efeito negativo sobre as leguminosas nativas, embora esse autor não tenha explicado se a presença das leguminosas foi resultado do chamado efeito "guardachuva", que ocorre quando a vazão e pressão de aplicação do herbicida é baixa e a densidade de espécies indesejáveis no estrato superior da pastagem é alta. Esse efeito "guardachuva" pode explicar ainda a pequena participação desta espécie no controle químico no segundo toque $(0,2 \%)$.

A participação de leguminosas na pastagem é extremamente importante, pois são plantas que realizam a fixação de nitrogênio no sistema e aumentam a qualidade da dieta animal. Os resultados deste trabalho foram obtidos em curto prazo (60 dias) e não podem indicar efeito deletério do herbicida à base de Picloram $+2,4 \mathrm{D}$ às leguminosas nativas em médio a longo prazo, pois a presença das leguminosas após o controle químico depende do banco de sementes no solo e do efeito residual do produto aplicado.

\section{Conclusões}

Os efeitos, a curto prazo, da prática de roçada ou da aplicação de herbicida Picloram +2,4D não se traduzem em aumentos significativos de produção de forragem. O controle químico possui alta eficiência de controle das espécies indesejáveis, apesar de eliminar a participação ou a frequência de leguminosas na massa de forragem disponível.

\section{Literatura Citada}

ALLEGRI, M. Mejoramiento de pasturas naturales. Control de malezas. In: REUNION DEL GRUPO TECNICO REGIONAL DEL CONO SUR EN MEJORAMIENTO Y UTILIZACIÒN DE LOS RECURSOS FORRAJEROS DEL AREA TROPICAL Y SUBTROPICAL, 1., 1978, Mercedes. Informe... Montevideo: extenso Instituto Interamericano de Cooperação para a Agricultura, 1978. p.120-132.

BECKER, D.A.; CROCKETT, J.J. Evaluation of sampling techniques on tall-grass prairie. Journal Ranger Management, v.26, n.1, p.61-67, 1973.

BOLDRINI, I.I. Campos do Rio Grande do Sul: caracterização fisionômica e problemática ocupacional. Porto Alegre: Universidade Federal do Rio Grande do Sul, 1997. 39p. (Boletim do Instituto de Biociências, 56).

DAMÉ, P.R.V.; ROCHA, M.G.; QUADROS, F.L.F.P. et al. Estudo florístico de pastagem natural sob pastejo. Revista Brasileira de Agrociência, v.5, n.1, p.45-49, 1999.

EMPRESA BRASILEIRA DE PESQUISA AGROPECUÁRIA EMBRAPA. Centro Nacional de Pesquisa do Solo - CNPS. Sistema Brasileiro de Classificação de solos. Rio de Janeiro: EMBRAPA, 1999. 412p.

ESCOSTEGUY, C.M.D. Avaliação agronômica de uma pastagem natural sob níveis de pressão de pastejo. Porto Alegre: Universidade Federal do Rio Grande do Sul, 1990. 231p. Dissertação (Mestrado em Zootecnia) - Universidade Federal do Rio Grande do Sul, 1990.

GIRARDI-DEIRO, A.M.; MOTA, A.F.; GONÇALVES, J.O.N. Efeito de roçadas no controle do alho-macho (Sisyrinchium platense 
Johnst.). Pesquisa Agropecuária Brasileira, v.34, n.6, p.1087-1091, 1999.

GOMES, K.E. Avaliação de pastagens modificadas pelo preparo do solo e introdução de espécies de inverno. Porto Alegre: Universidade Federal do Rio Grande do Sul, 1984. 121p. Dissertação (Mestrado em Agronomia) - Universidade Federal do Rio Grande do Sul, 1984.

GONZAGA, S.S. Controle de plantas invasoras (melhoramento do campo nativo visando o aumento na capacidade de suporte da pastagem natural, através de práticas de manejo). In: EMBRAPA, Ministério da Agricultura e Planejamento (Eds.) Plano de safra 1998/99. Seminários técnicos sobre a produção de carne de qualidade para o Rio Grande do Sul, Santa Catarina e Paraná. Bagé: Embrapa Pecuária Sul, 1999. p.42-49.

HARRIS, W. Defoliation as a determinant of the growth, persistence and composition of pasture. In: WILSON, J.R. (Ed.) Plant relations in pastures. Melbourne: CSIRO, 1978. p.67-85.

MONTEFIORI, M.; VOLA, E. Efecto de competencia de las malezas Eryngium horridum (cardilla) y Baccharis coridifolia (mio mio) sobre la producción del campo natural em suelos de la unidade "La Carolina". In: SEMINÁRIO NACIONAL DE CAMPO NATURAL, 2., 1990, Tacuarembó. Anais... Tacuarembó: Hemisferio Sur, 1990. p.125-132.

MOOJEN, E.L. Dinâmica e potencial produtivo de uma pastagem nativa do Rio grande do Sul submetida a pressões de pastejo, épocas de diferimento e níveis de adubação. Porto Alegre: Universidade Federal do Rio Grande do Sul, 1991. 172p. Tese (Doutorado em Zootecnia) Universidade Federal do Rio Grande do Sul, 1991.

MORAES, A.; MARASCHIN, G.E.; NABINGER, C. et al. Pastagens nos ecossistemas de clima subtropical: pesquisas para o desenvolvimento sustentável. In: SIMPÓSIO SOBRE PASTAGENS NOS ECOSSISTEMAS BRASILEIROS, 1995, Brasília. Anais... Brasília: Sociedade Brasileira de Zootecnia, 1995. p.47-200.

Moreno, J.A. Clima do Rio Grande do Sul. Porto Alegre: Secretaria da Agricultura, 1961. 41p.

NABINGER, C. Sistema de pastoreio e alternativas de manejo de pastagens. In: CICLO DE PALESTRAS EM PRODUÇÃO E MANEJO DE BOVINOS DE CORTE, 7., 2002, Canoas. Ênfase: manejo reprodutivo e sistemas de produção em bovinos de corte Anais... Canoas: Universidade Luterana do Brasil, 2002. p.7-60.

NABINGER, C. Técnicas de melhoramento de pastagens naturais no Rio Grande do Sul. In: SEMINÁRIO SOBRE PASTAGENS "DE QUE PASTAGENS NECESSITAMOS”, 1980, Porto Alegre. Anais... Porto Alegre: Federação da Agricultura do Rio Grande do Sul, 1980. p.28-58.

NUÑEZ, H.; DEL PUERTO, O. Biologia de Baccharis trimera. In: REUNION DEL GRUPO TÉCNICO REGIONAL DEL CONO SUR EN MEJORAMIENTO Y UTILIZACIÓN DE LOS RECURSOS FORRAGEROS DEL ÁREA TROPICAL Y SUBTROPICAL - GRUPO CAMPOS Y CHACO. 9. 1987. Tacuarembó. Anais... Tacuarembó: Grupos Campos y Chacos, 1988. p.99-102.

PACHECO, B.M.; NASCIMENTO JR., D.; REGAZZI, A.J. Comparação de métodos para estimativa da composição botânica de pastagem. Revista da Sociedade Brasileira de Zootecnia v.16, n.4, p.337-351, 1987.

ROCHA, G.L. Ecossistema de pastagens - aspectos dinâmicos Piracicaba: Fundação de Estudos Agrários Luiz de Queiroz, 1991. $391 \mathrm{p}$.

SANTOS, M.V.F.; NASCIMENTO JR., D.; PEREIRA, J.C. et al. Composição florística, densidade e altura de uma pastagem natural sob pastejo. Revista Brasileira de Zootecnia, n.6, p.1082-1091, 1998.

STATISTICAL ANALYSIS SYSTEM - SAS. SAS language reference. Version 6. Cary: 1993. 1042p.

SOUZA, A.G. Determinação do rendimento e da composição botânica de uma pastagem natural. Santa Maria: Universidade Federal de Santa Maria, 1985. 120p. Dissertação (Mestrado em Zootecnia) - Universidade Federal de Santa Maria, 1985.

VITORIA FILHO, R. Fatores que influenciam a absorção foliar dos herbicidas. Informe Agropecuário, v.11, n.129, p.31-38, 1985.

Recebido: $16 / 6 / 2006$ Aprovado: 26/3/2007 